\title{
Long-Term Visual Function Effects of Pan-Retinal Photocoagulation in Diabetic Retinopathy and Its Impact in Real Life
}

This article was published in the following Dove Press journal: Diabetes, Metabolic Syndrome and Obesity: Targets and Therapy

\author{
Pedro Manuel Baptista (1D) 1,2 \\ Ana Ambrósio Marta $\mathbb{D}^{1,2}$ \\ João Heitor (DI) \\ Diana José (iD) \\ Daniel Almeida' \\ António Ribeiro' \\ Irene Barbosa $\mathbb{( D}^{1,2}$
}

'Ophthalmology Department, Centro Hospitalar Universitário do Porto, Porto, Portugal; ${ }^{2}$ Instituto de Clências Biomédicas Abel Salazar, Universidade do Porto, Porto, Portugal
Correspondence: Pedro Manuel Baptista Centro Hospitalar Universitário do Porto, Largo Prof. Abel Salazar, Porto, 4099-00I, Portugal

Email pedroyybaptista@gmail.com
Purpose: To address the long-term visual function after bilateral pan-retinal photocoagulation (PRP) and its impact in real life, namely on visual field (VF) legal criteria to drive. To determine potential predictors related to clinical factors and treatment strategies.

Patients and Methods: Observational cross-sectional study. Eyes from diabetic patients diagnosed with diabetic retinopathy who underwent bilateral PRP, with or without macular treatments and with visual acuity legal criteria for non-professional driving were randomly assigned. Main outcomes were: demographic and clinical data including best corrected visual acuity; binocular visual field (EBST-Esterman Binocular Suprathreshold Test, Humphrey analyzer $\left.3^{\circledR}\right)$; contrast sensitivity (CS-Metrovision-MonPack $3{ }^{\circledR}$ ); light scattering in the retina (HD Analyzer, Visiometrics ${ }^{\circledR}$ ).

Results: Seventy-one diabetic patients included (44 men and 27 women), with a mean age of $62.2 \pm 11.8$ years. PRP was performed, on average, $9.7 \pm 6.9$ years before the study. The average EBST Score was $85.8 \pm 17.0$ and the average CS $(2-5 \mathrm{cpd})$ was $19.5 \pm 2.9 \mathrm{~dB}$ in photopic and $14.2 \pm 4.1 \mathrm{~dB}$ in mesopic conditions. Through a multivariate regression model, after adjusting to the clinical and demographic factors as possible confounders, we found that treatment factors associated with worse results were the use of Argon laser for the EBST Score, the very confluent PRP for the number of non-viewed points in the central $30^{\circ} \times 20^{\circ}$ of the EBST and the presence of macular treatments for the CS tests. According to Portuguese law, 79\% $(n=56)$ of patients had minimal EBST amplitudes for non-professional driving.

Conclusion: The functional results achieved in our sample are compatible with an active life, allowing most of the patients included to overcome the requirements of Portuguese legislation for driving light vehicles, namely at the level of the binocular visual field. These results highlight the role of PRP in the treatment of diabetic retinopathy in an era with evolving less aggressive laser options.

Keywords: diabetic retinopathy, pan-retinal photocoagulation, retinal laser, Esterman binocular visual field, contrast sensitivity

\section{Introduction}

Pan-retinal photocoagulation (PRP) has become the gold standard for the treatment of proliferative diabetic retinopathy (PDR) since 1976, by the time the Diabetic Retinopathy Study Research Group ${ }^{1}$ demonstrated a reduction in the rate of visual loss with laser treatment. Thereafter, several analyses ${ }^{2-5}$ were conducted by the same scientific group in order to evaluate the structural and functional results. Despite having demonstrated its effectiveness, they highlighted the harmful 
potential to the retinal and choroidal tissues, with risk of functional impact, particularly on visual fields (VF).

The evolution of lasers from conventional to a diversity of multispot and subthreshold systems, capable of reducing exposure times and using different wavelengths with different absorption spectra, has increased the options of treatment strategies, presenting different potential for harm and theoretically less impact on daily life activities; ${ }^{6}$ however, data available in the literature regarding the effects of PRP is limited mainly due to small sample sizes, short follow-up periods and the evaluation of treatments with non-standardised parameterizations.

In practice, PRP can have a real functional impact and be a handicap in daily living for active people, particularly driving. Acquiring and maintaining the driving license has long been a concern for the population with DR undergoing bilateral PRP, ${ }^{7-12}$ and this may be, at the same time, a way to address the functional results of the procedure in real-life studies. Visual acuity is the major, and most of the times, inadequately the only requirement for maintaining driving license. However, even individuals with good central vision in photopic conditions can have impairment in other important visual functions like night vision or visual field. In this sense, the main purpose of the present work is to quantify in a more comprehensive way the visual function of patients submitted to bilateral PRP and with visual acuity legal criteria to drive light vehicles and address its impact in real life. Additionally, we aimed to built a multivariable regression model to determine potential independent predictors of these functional outcomes related to clinical factors and treatment strategies.

\section{Patients and Methods Design}

Observational cross-sectional study set at the Ophthalmology Department, Centro Hospitalar e Universitário do Porto, Porto, Portugal, a tertiary center. The study followed the tenets of the Declaration of Helsinki. Approval was obtained from the "Departamento de Ensino, Formação e Investigação" (DEFI), no. 144-20 (114-DEFI/116-CE). Written informed consent was waived due to total anonymization and confidentiality of the data and the absence of detailed individual clinical information.

\section{Population}

Diabetic patients diagnosed with DR and submitted to bilateral PRP with or without macular and/or focal photocoagulation in the posterior pole. The criterion for patient selection was minimum visual acuity for driving light vehicles (group 1), according to Decree-Law no. 40, $07 / 29 / 2016::^{13}$ binocular visual acuity of at least 0.5 (decimal), with or without optical correction, or visual acuity of at least 0.6 (decimal), with or without optical correction, in cases of monocularity. The presence of corneal diseases, concurrent macular diseases, in-treatment active macular edema, ${ }^{14}$ optic nerve diseases other than glaucoma, history of amblyopia and impaired ability to perform functional tests due to neurological or psychiatric status were considered exclusion criteria.

\section{Laser Treatments}

Treatments were performed with Argon (514 nm) $\left(\right.$ Coherent $\left.{ }^{\circledR}\right)$ and Double frequency nd:YAG monospot (nd:YAGII) $(532 \mathrm{~nm})\left(\right.$ ZEISS $\left.^{\circledR}\right)$ and multispot $\left(\right.$ Valon $^{\circledR}$ ) lasers. The most frequently used timing was $100 \mathrm{~ms}$ for the Argon laser, and 20-30 ms for the nd:YAGII. The spot size used was 50 or $100 \mu \mathrm{m}$ for the macular or focal photocoagulation at the posterior pole, 200 to $250 \mu \mathrm{m}$ for the photocoagulation adjacent to vascular arcades, and 200 to $500 \mu \mathrm{m}$ in the periphery, depending on the media opacity and magnification of the contact lenses used, among other factors. The contact lenses used for the treatments were: Mainster focal lens $\left(\right.$ Ocular $\left.^{\circledR}\right)$ for macular photocoagulation, in the posterior pole and adjacent to the vascular arcades and panfundoscopic lens, namely, Mainster lens PRP 165 (Ocular $^{\circledR}$ ) and 3 mirror lens $\left(\operatorname{Occular}^{\mathbb{R}}\right)$ for photocoagulation of the peripheral retina. The power applied was selected in order to allow visualization of the whitish marks resulting from the impacts on the retina.

\section{Data Gathering}

Demographic and clinical data were obtained through analysis of patients' clinical records. Data were collected regarding: age; gender; type and duration of diabetes (tD); duration of the DR (tDR); best corrected visual acuity, at a distance of 6 meters, on the decimal scale (BCVA); lens status; history of diabetic macular edema (DME) and/or intravitreal injections of anti-vascular endothelial growth factor (VEGF) or corticosteroids; history of glaucoma or ocular hypertension (OHT); concomitance of pathology or previous vitreoretinal (VR) surgery; history of peripheral retinal cryoablation (PRC); type of laser; time since PRP (tPRP).

Retinal photocoagulation characteristics were obtained by analysing all clinical records, retinographs and previous 
angiographies, all recorded by the same physician. Regarding PRP, three patterns were considered, according to the predominance of the following aspects: non-confluent, when the marks of the various impacts were observed individually, with spacing between them greater than one-mark size; confluent, when this spacing was equal or less than onemark size; very confluent, when there was coalescence of the various marks. Additionally, the quantification of the total treated area was calculated based on the sum of the various impacts made in different photocoagulation sessions, with reduction of the various spot sizes to a $250 \mu \mathrm{m}$ spot size area. Photocoagulation within the posterior pole was divided into two categories: focal and in the form of a macular temporal horseshoe (modified macular grid), always preserving the papillomacular bundle. Figure 1 shows examples of different combinations of peripheral and macular treatment patterns.

Visual function was assessed in different ways other than the BCVA: visual field (VF), contrast sensitivity (CS) and retinal light scattering. The VF was analysed using the Esterman Binocular Suprathreshold Test (EBST) (Humphrey Analyzer $3{ }^{\circledR}$; central fixation target, white III stimulus, 31.5 asb background, two zone strategy, agecorrected, central and peripheral references of $34 \mathrm{~dB}$ ) by measuring the amplitudes in each direction, the Esterman Efficiency Score (EES) and the number of non-viewed points within the central square of the horizontal $30^{\circ}$ and vertical $20^{\circ}\left(\mathrm{NVP} 30^{\circ} \times 20^{\circ}\right)$ and in each quadrant. Regarding the $\mathrm{CS}$, we analysed the function both under photopic (PCS) and mesopic conditions (MCS) in the various spatial frequencies (Metrovision-MonPack $3{ }^{\circledR}$; static, grating luminance's of $80 \mathrm{~cd} / \mathrm{m}^{2}$ in the photopic exam and $0.08 \mathrm{~cd} / \mathrm{m}^{2}$ in the low mesopic exam). Through the HD Analyser ${ }^{\circledR}$ technology, light scattering was objectively measured across the ocular media (Objective Scatter Índex, OSI) and ocular contrast sensitivity function without optic nerve and cortical compounds was addressed
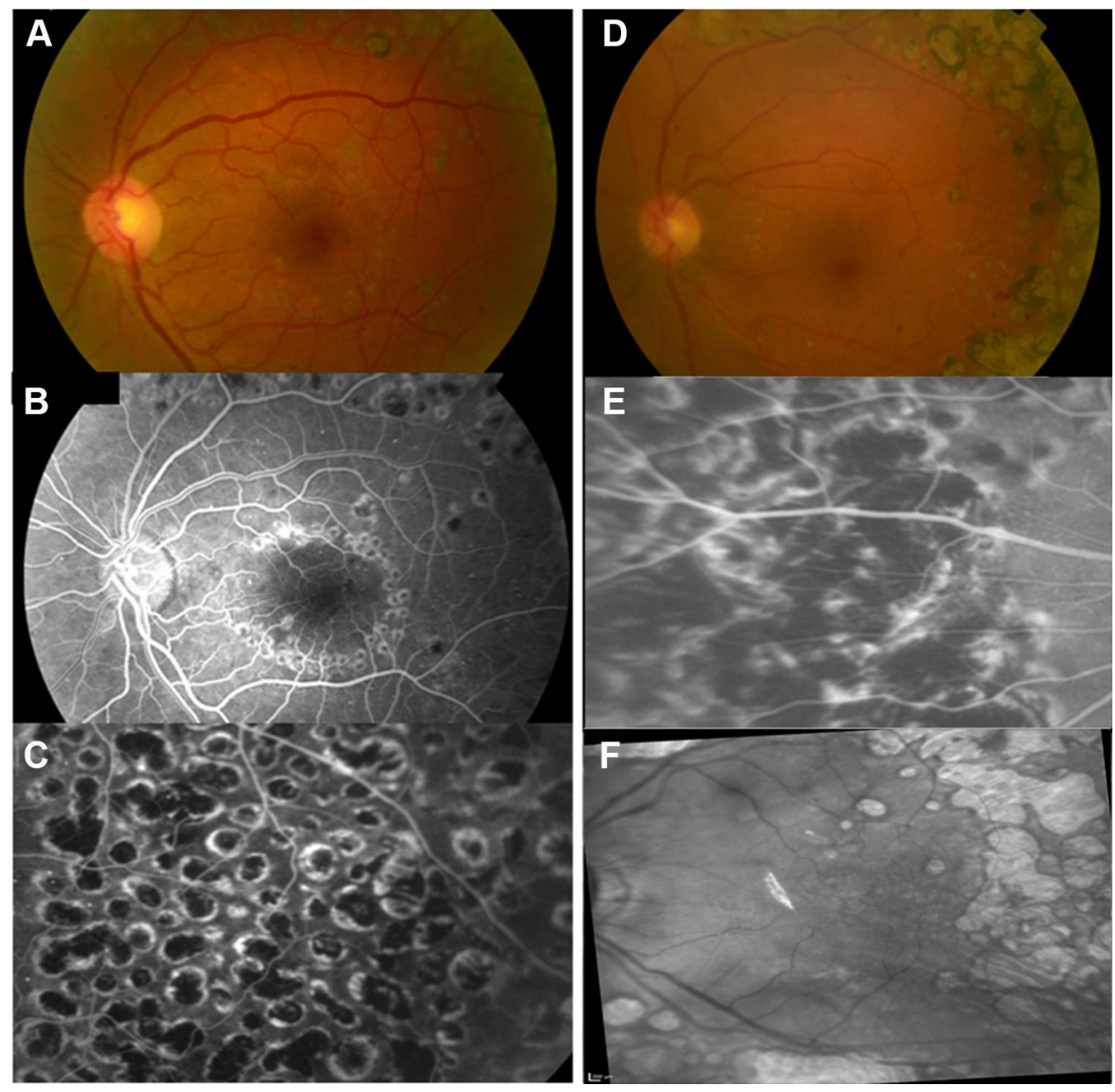

Figure I Examples of treatment patterns. (A-C) patient I; (D) and (E) patient 2; (F) patient 3. (A) Fundus photography; (B) macular temporal horseshoe, fluorescein angiography; (C) confluent PRP pattern, fluorescein angiography; (D) fundus photography; (E) very confluent PRP pattern, fluorescein angiography; (F) macular focal treatment, fluorescein angiography. 
(Modular Transfer Function, MTF), both for a pupil size of $4 \mathrm{~mm}$.

\section{Real-Life Impact Measurement}

The impact of PRP on real life was assessed evaluating the interference of the binocular visual field test with the ability to drive light vehicles. According to the aforementioned Decree-Law, the visual field must meet the following requirements: be at least $120^{\circ}$ in the horizontal plane and have a minimum extension of $50^{\circ}$ to the left and right, and $20^{\circ}$ to the top and bottom, and the absence of defects within a radius of $20^{\circ}$ from the central axis.

\section{Statistical Analysis}

All analyses were performed using the SPSS ${ }^{\circledR}$ and Stata ${ }^{\circledR}$ softwares. Data normality was tested with Shapiro-Wilk and Kolmogorov-Smirnov tests. Levene's test was applied to assess homogeneity of variances. When parametric analysis could be applied, the Student's $t$-test was used to compare the variables. When nonparametric tests were needed, the Wilcoxon rank-sum test was applied. The $\chi^{2}$ was used to compare nominal and ordinal variables. Spearman's rank correlation coefficient was used to correlate variables.

The candidate predictors in multivariable analyses were treatment characteristics and patients' demographic and clinical factors. Predictors were screened in order to identify associations with BCVA, EES, NVP $30^{\circ} \times 20^{\circ}, \mathrm{PSC}$ and MCS at the $p<0.25$ level. Predictors meeting this criterion were included in a stepwise, backward analysis in which $p<0.05$ served as the criterion for inclusion into the full model- exceptions were made when clinically appropriate.

All values are shown as mean \pm standard deviation unless otherwise specified. All p-values (p) were 2-sided, and $p$-values $<0.05$ were considered significant.

\section{Results}

\section{Demographics and General Descriptions}

The study population consisted of 142 eyes of 71 diabetic patients who underwent PRP, divided into 44 (62\%) men and 27 (38\%) women, with a mean age of $62.2 \pm 11.8$ [38-86] years. As for the type of disease, 29 (41\%) had type 1 and 42 (59\%) had type 2 diabetes. The Argon laser $(514 \mathrm{~nm})$ was used in the majority $(63 \%, \mathrm{n}=89)$ of eyes. The most common PRP pattern was the confluent $(73 \%$, $n=104)$ and the majority $(85 \%, n=120)$ of eyes underwent posterior pole laser treatments. Clinical, demographic and treatment data are in Tables 1 and 2.

\section{Visual Acuity}

The mean of BCVA was 0.71 , with 62 (44\%) of the eyes reaching 0.8 or better on the decimal scale. Eyes with cataract $(\mathrm{p}=0.010)$ had lower BCVAs. There were no significant differences within the different treatment subgroups $(\mathrm{p}>0.05)$ (Tables 3 and 4). Higher age was associated with lower BCVA $(r=-0.408, \mathrm{p}<0.001)$.

\section{Visual Field}

The averages of both the visual field amplitudes and the non-viewed points in each quadrant on the EBST are within Figure 2. The average EES achieved was 85.8 \pm 17.0 and the average of points seen was $103.8 \pm 20.0$ out of 120 possible.

Patients treated with Argon laser $(\mathrm{p}<0.001)$, those treated with very confluent pattern $(\mathrm{p}<0.001)$ and patients with history of VR surgery $(p=0.001)$ or PRC $(p=0.008)$ obtained significantly lower EES (Tables 3 and 4). A lower EES was negatively correlated with higher age $(\mathrm{r}=-2.47, \mathrm{p}=0.003), \mathrm{tD} \quad(\mathrm{r}=-0.356, \mathrm{p}<0.001), \mathrm{tDR} \quad(\mathrm{r}=$ $-0.431, \mathrm{p}<0.001)$ and tPRP $(\mathrm{r}=0.510, \mathrm{p}<0.001)$.

Centering the analysis on the macular area, the mean NVP30 $0^{\circ} 20^{\circ}$ was $1.9 \pm 4.4$ within 54 possible. The groups with Argon Laser $(\mathrm{p}=0.001)$ and very confluent PRP pattern $(p<0.001)$ had higher values. On the other hand, the macular treatment characteristics did not influence significantly the outcome $(\mathrm{p}>0.05)$. History of VR surgery $(p=0.005)$ was the only clinical factor associated with a higher value (Tables 3 and 4 ). The NVP30 $0^{\circ} \times 20^{\circ}$ was positively correlated with $\mathrm{tD}(\mathrm{r}=0.337, \mathrm{p}<0.001)$, with tDR $(\mathrm{r}=0.445, \mathrm{p}<0.001)$, with tPRP $(\mathrm{r}=0.516, \mathrm{p}<0.001)$ and the number of impacts $(\mathrm{r}=0.212, \mathrm{p}=0.013)$.

\section{Contrast Sensitivity}

The curves obtained through the average values of the PCS and MCS in each special frequency range are shown in Figure 3. Overall, the loss tended to be greater at higher spatial frequencies, both in photopic and mesopic conditions.

In the analysis centered on the $2-5 \mathrm{cpd}$ interval, near normal PCS $(19.5 \pm 2.9 \mathrm{~dB})$ and subnormal MCS $(14.2 \pm 4.1$ $\mathrm{dB})$ on average were found. In the PCS test, eyes treated with Argon laser $(\mathrm{p}=0.033)$, those who had macular treatments $(p<0.001)$ and eyes with cataract $(p=0.005)$ had lower values. In the MCS, eyes who had macular 
Table I Clinical and Demographic Data: Overall and per Type of Diabetes Analysis

\begin{tabular}{|c|c|c|c|c|}
\hline & $\begin{array}{c}\text { All Sample } \\
\text { I42 Eyes }\end{array}$ & $\begin{array}{c}\text { TI } \\
58 \text { Eyes }\end{array}$ & $\begin{array}{c}\text { T2 } \\
84 \text { Eyes }\end{array}$ & TI vs T2 (p) \\
\hline Age (years) & $62.2 \pm 11.8$ & $53.1 \pm 10.6$ & $68.4 \pm 8.1$ & $<0.001$ \\
\hline tD (years) & $32.7 \pm 8.6$ & $36.0 \pm 7.8$ & $30.5 \pm 8.5$ & $<0.001$ \\
\hline tDR (years) & $18.1 \pm 8.7$ & $21.8 \pm 9.0$ & $15.5 \pm 7.5$ & $<0.001$ \\
\hline tPRP (years) & $9.7 \pm 6.9$ & $12.3 \pm 8.3$ & $7.8 \pm 5.0$ & $<0.001$ \\
\hline $250 \mu \mathrm{m}$ Spots (nr) & $5825 \pm 2353$ & $6581 \pm 2700$ & $5263 \pm 1889$ & 0.002 \\
\hline \multicolumn{5}{|c|}{ Lens status, n (\% within group) } \\
\hline Transparent & $24(17 \%)$ & $20(34 \%)$ & $4(5 \%)$ & $<0.001$ \\
\hline Cataract & $50(35 \%)$ & $21(36 \%)$ & $29(35 \%)$ & 0.86 \\
\hline Pseudophakic & $68(48 \%)$ & 17 (29\%) & $51(61 \%)$ & $<0.001$ \\
\hline \multicolumn{5}{|c|}{$\begin{array}{l}\text { Ophthalmological history, n (\% within } \\
\text { group) }\end{array}$} \\
\hline OHT/Glaucoma & 27 (19\%) & $8(14 \%)$ & $19(23 \%)$ & 0.19 \\
\hline DME & $46(32 \%)$ & 14 (24\%) & $32(38 \%)$ & 0.081 \\
\hline Anti-VEGF/Corticosteroid & $15(11 \%)$ & $2(3 \%)$ & $13(15 \%)$ & 0.026 \\
\hline VR pathology & $40(28 \%)$ & $18(31 \%)$ & $22(26 \%)$ & 0.40 \\
\hline ERM & 19 & 5 & 14 & \\
\hline $\mathrm{VH}$ & 14 & 8 & 6 & \\
\hline $\mathrm{RD}$ & 6 & 5 & 1 & \\
\hline $\mathrm{MH}$ & I & 0 & I & \\
\hline VR surgery & $23(16 \%)$ & $13(22 \%)$ & $10(12 \%)$ & 0.095 \\
\hline PRC & 17 (12\%) & II (19\%) & $6(7 \%)$ & $<0.001$ \\
\hline
\end{tabular}

Notes: Statistical significance at $\mathrm{p}<0.05$. TI: type I diabetics, T2: type 2 diabetics, $t D$ : time since diabetes diagnosis, $t D$ : time since diabetic retinopathy diagnosis. Abbreviations: tPRP, time since pan-retinal photocoagulation; OHT, ocular hypertension; DME, diabetic macular edema; Anti-VEGF, anti-vascular endothelial growth factor and/or corticosteroids; VR, vitreo-retinal; ERM, epiretinal membrane; VH, vitreous hemorrhage; $\mathrm{MH}$, macular hole; PRC, peripheral retinal cryoablation.

Table 2 Photocoagulation Treatment Data: Overall and per Type of Diabetes Analysis

\begin{tabular}{|l|c|c|c|}
\hline & $\begin{array}{c}\text { All Sample } \\
\text { I 42 Eyes }\end{array}$ & $\begin{array}{c}\text { TI } \\
\mathbf{5 8} \text { Eyes }\end{array}$ & $\begin{array}{c}\text { T2 } \\
\mathbf{8 4} \text { Eyes }\end{array}$ \\
\hline $\begin{array}{l}\text { Type of laser, n (\% within group) } \\
\text { Argon } \\
\text { nd:YAGII }\end{array}$ & $89(63 \%)$ & $42(72 \%)$ & $47(56 \%)$ \\
\hline Pattern of PRP, n (\% within group) & $53(37 \%)$ & $16(28 \%)$ & 0.046 \\
Non-confluent & $2(1 \%)$ & $0(0 \%)$ & $2(2 \%)$ \\
Confluent & $104(73 \%)$ & $40(69 \%)$ & $64(76 \%)$ \\
Very confluent & $36(25 \%)$ & $18(31 \%)$ & $18(21 \%)$ \\
\hline Macular treatments, n (\% within group) & $22(16 \%)$ & $13(22 \%)$ & $9(11 \%)$ \\
$\quad$ No treatment & $62(44 \%)$ & $22(38 \%)$ & $40(48 \%)$ \\
Focal & $58(41 \%)$ & $23(40 \%)$ & $35(42 \%)$ \\
Modified grid & & 0.15 \\
\hline
\end{tabular}

Note: Statistical significance at $\mathrm{p}<0.05$.

Abbreviations: Argon, Argon laser (514 nm, Coherent $\left.{ }^{\circledR}\right)$; nd:YAGIl: Double frequency nd:YAG (532 nm) monospot $\left(\right.$ ZEISS $\left.{ }^{\circledR}\right)$ and multispot $\left(\right.$ Valon $\left.{ }^{\circledR}\right)$ lasers. 


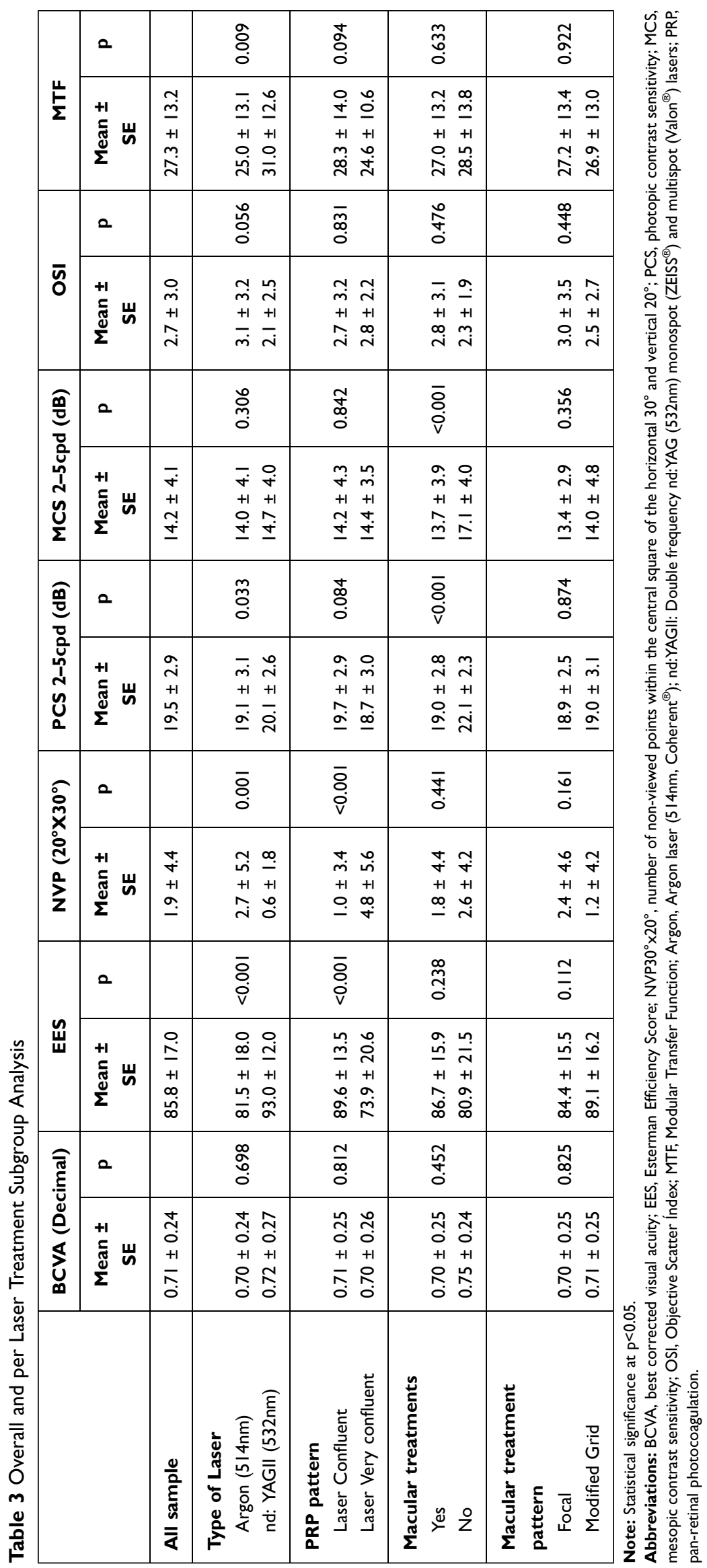




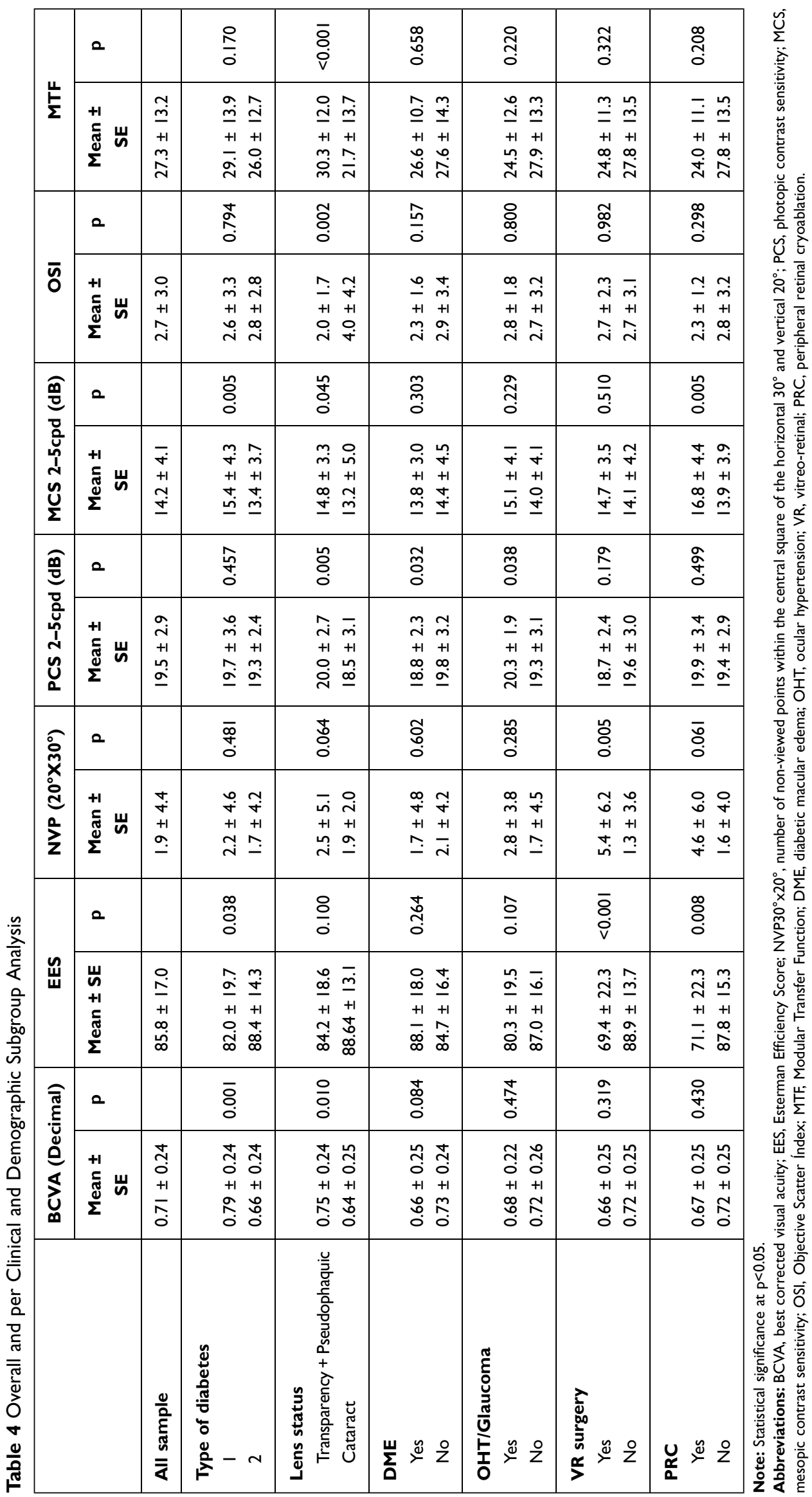




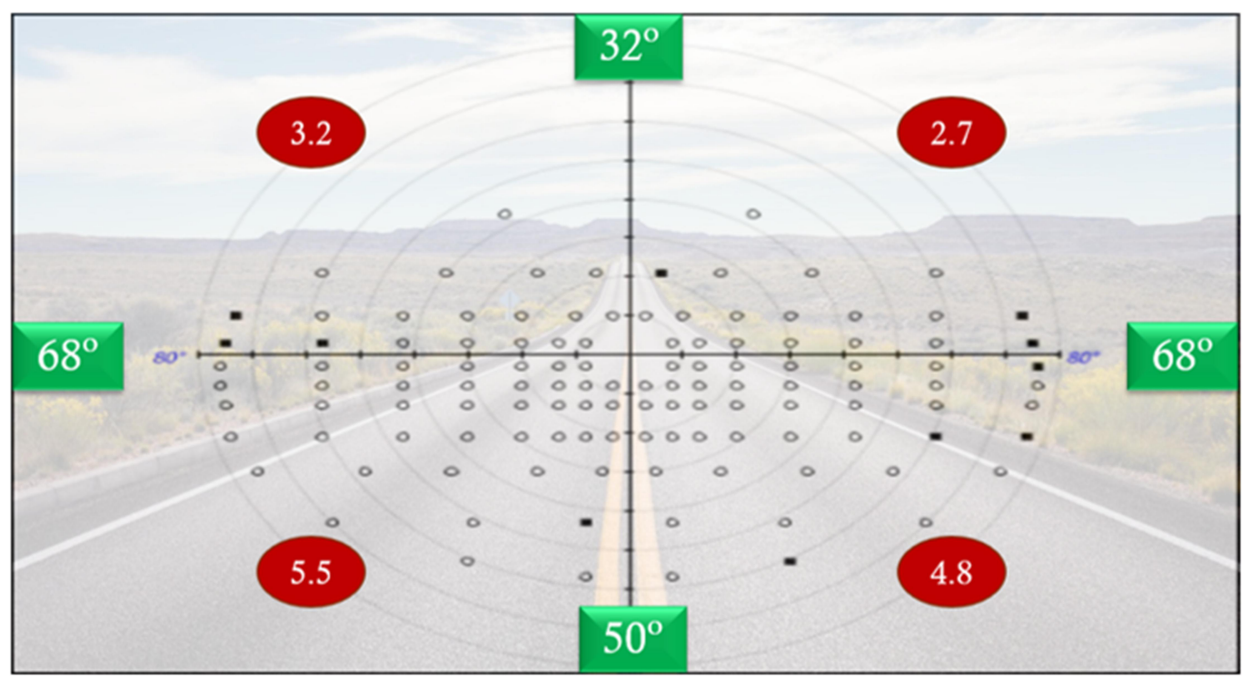

Figure 2 Example of an Esterman binocular visual field test printout. Green squares: mean visual field amplitudes $\left({ }^{\circ}\right)$ of the sample; red circles: average non-viewed points per quadrant, in all sample.

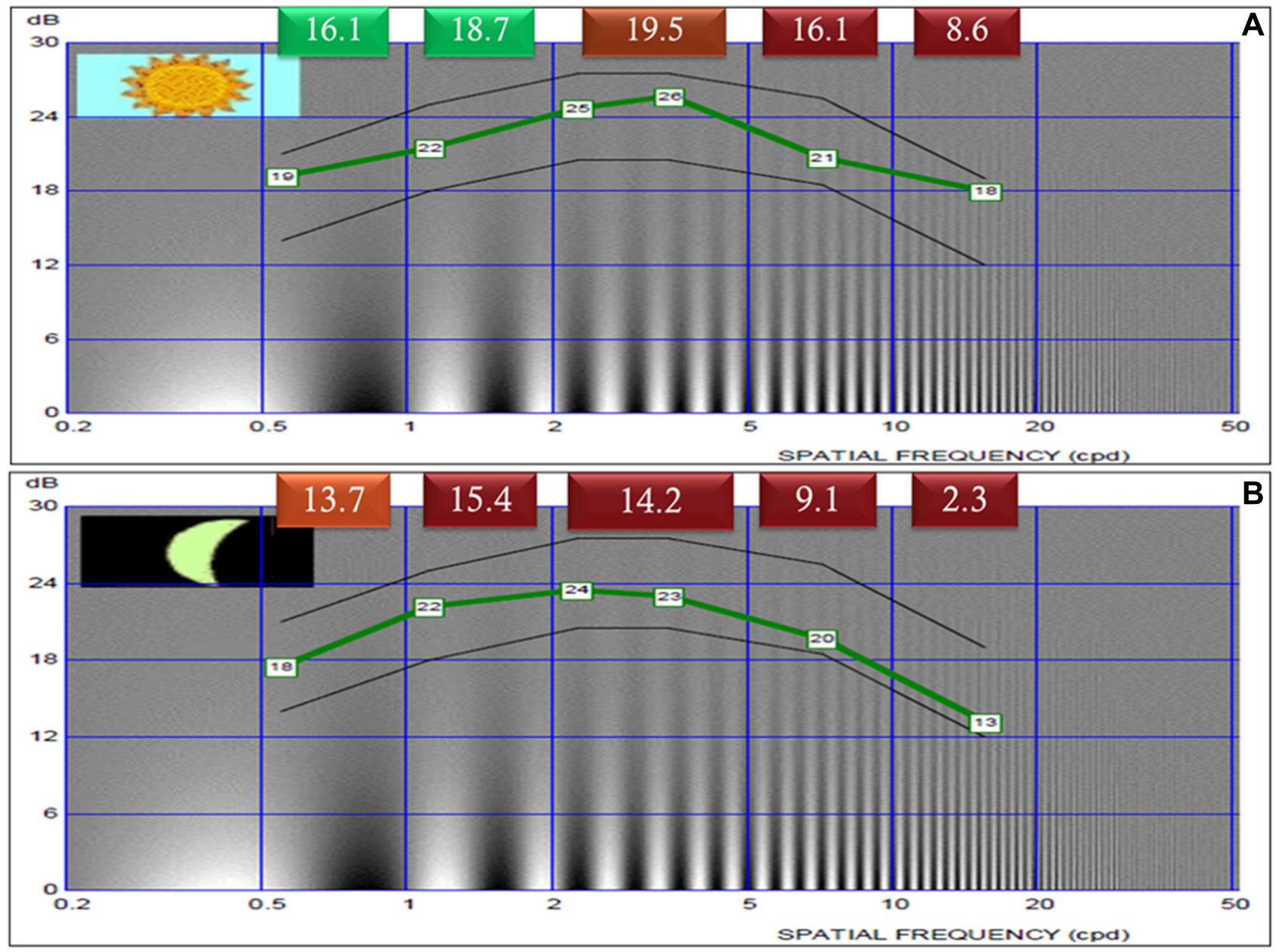

Figure 3 Example of a theoretical contrast sensitivity (dB) curve in photopic (A) and mesopic (B) conditions. Green line: normal theoretical curve; green, orange and red squares: mean values $(\mathrm{dB})$ of the sample in each spatial frequency interval. 
treatments $(\mathrm{p}<0.001)$ and those with history of PRC $(p=0.005)$ or presence of cataract $(p=0.045)$ had lower values (Tables 3 and 4). Lower PCS and MCS in the 2 $5 \mathrm{cpd}$ interval were associated with higher age $(\mathrm{r}=-0.232$, $\mathrm{p}=0.005$ and $\mathrm{r}=-0.343, \mathrm{p}<0.001$, respectively) and OSI ( $\mathrm{r}=$ $-0.358, \mathrm{p}<0.001$ and $\mathrm{r}=-0.376, \mathrm{p}<0.001$, respectively) and lower BCVA $(\mathrm{r}=0.445, \mathrm{p}<0.001$ and $\mathrm{r}=0.417, \mathrm{p}<0.001$, respectively) and $\operatorname{MTF}(r=0.335, \mathrm{p}<0.001$ and $\mathrm{r}=0.362$, $\mathrm{p}<0.001$, respectively) values.

\section{Light Scattering}

Patients reached global mean values of $2.7 \pm 3.0$ in the OSI and $27.3 \pm 13.2$ in the MTF. Eyes with cataract had higher mean OSI values $(p=0.002)$ and lower MTF $(p<0.001)$. Eyes treated with Argon laser had lower MTF ( $p=0.009)$ (Tables 3 and 4). Higher OSI and lower MTF were associated with older age $(r=0.395, \mathrm{p}<0.001$ and $\mathrm{r}=-0.279$, $\mathrm{p}=0.001$, respectively) and with higher tPRP $(\mathrm{r}=0.240$, $\mathrm{p}=0.004$ and $\mathrm{r}=-0.178, \mathrm{p}=0.036$, respectively).

\section{Comparison by Type of Diabetes}

Patients with type 1 diabetes were younger but had longer tD $(p<0.001)$, tDR $(p<0.001)$ and tPRP $(p<0.001)$ and higher number of spots $(p=0.002)$ and PRC history $(p<0.001)$. The proportion of eyes with cataracts was similar in the two groups $(\mathrm{p}=0.86)$ but more eyes underwent anti-VEGF within type 2 group $(\mathrm{p}=0.026)$. The proportion of eyes who underwent Argon laser treatments was higher within type 1 diabetics $(\mathrm{p}=0.046)$ (Tables 1 and 2). Assessing the functional results, eyes from type 1 diabetics had higher BCVA $(p=0.001)$ and $\operatorname{MCS}(p=0.005)$, but lower EES ( $\mathrm{p}=0.038)$ (Tables 3 and 4).

\section{Multivariable Regression Analysis}

A multivariable regression model was built to determine potential independent predictors of the functional outcomes and adjust for potential confounders (Table 5). Older age and cataract were independent predictors for worse BCVA. Older age, type 1 diabetes, Argon laser therapy, history of PRC or VR surgery were independent predictors for lower EES. Older age, history of PRC and very confluent PRP pattern were independent predictors of higher NVP $30^{\circ} \times 20^{\circ}$. Older age, presence of cataract, the number of spots and macular treatments were independent predictors for lower PCS 2-5cpd and MCS 2-5cpd. Additionally, history of VR surgery or OHT/Glaucoma were independent predictors only for the PCS $2-5 \mathrm{cpd}$.
Neither tD, tDR or tPRP were independent predictors of the functional outcomes.

\section{Discussion}

The present work is a real-world study, which is aimed to expose the real-life functional results of bilateral PRP nearly 10 years after the treatment in average. Because DR and DME share most of risk factors, ${ }^{15}$ eyes with PDR are more prone to develop DME with need of intravitreal treatments and, not rarely, more invasive treatments like PRC or VR surgery. Additionally, the higher prevalence of glaucoma in PDR eyes has been reported many years ago. ${ }^{16}$ Thus, the authors did not exclude these eyes as it could preclude the aimed real-life analysis. However, patients without the minimum legal BCVA requirements to drive were excluded for three reasons: first, after analyzing the initial sample, those patients were found to have high proportion of concurrent important factors that could skew the results of $\mathrm{CS}$ and $\mathrm{VF}$, like dense cataracts, chronic DME with external retinal impairment or terminal neovascular glaucoma; second, most of these problems are related to the natural history and degree of the disease itself, being confounding factors; third, most had other cardiovascular/cerebrovascular comorbidities with decreased capability of performing the visual tests.

In fact, even after the application of the inclusion and exclusion criteria, the prevalence of some clinical confounders in the sample is of notice, namely cataract $(35 \%)$, history of DME $(32 \%)$. In the comparative analysis, worse results were found in eyes with cataract regarding BCVA, light scattering, and contrast sensitivity functions but only regarding PCS in eyes with DME history. This highlight the complexity of these patients and the need of an adjusted analysis when the aim is to find treatment-related predictors of prognosis.

The sample presented very good results regarding BCVA, with approximately $44 \%$ of eyes reaching a BCVA of 0.8 or more; however, one should keep in mind that patients with low BCVA not compatible with the legal title for driving non-professional vehicles were excluded, as aforementioned. However, it should be highlighted that no treatment-related factors were associated with significant differences after the adjustment for cataract and age as confounders.

The global average of OSI was only slightly lower than the normal reference intervals. After adjusting for cataract as a confounder, we could infer that laser treatments do not 


\begin{tabular}{|c|c|c|c|c|c|c|c|}
\hline$\frac{\widehat{\underline{m}}}{\mathrm{v}}$ & 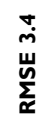 & $a$ & $\tilde{z}$ & $\tilde{z}$ & $\begin{array}{l}\bar{\delta} \\
\text { i } \\
\text { v }\end{array}$ & $\tilde{z} \tilde{z}$ & ঃั: \\
\hline 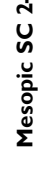 & $\begin{array}{l}\frac{\circ}{M} \\
\sim \widetilde{\sim}\end{array}$ & 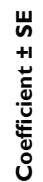 & 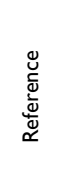 & 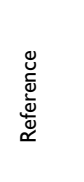 & $\begin{array}{l}0 \\
0 \\
+1 \\
\hat{0} \\
\hat{\rho}\end{array}$ & 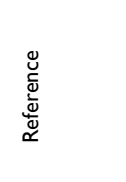 & $\begin{array}{l}\overline{0} \\
0 \\
+1 \\
+1 \\
\text { वे }\end{array}$ \\
\hline
\end{tabular}

\begin{tabular}{|c|c|c|c|c|c|}
\hline 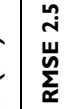 & a & $\tilde{z}$ & $\tilde{z} \tilde{z}$ & $\tilde{z}$ & $\begin{array}{ll}\bar{\partial} & \bar{o} \\
\dot{i} & 0 \\
\dot{i}\end{array}$ \\
\hline 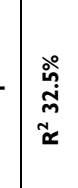 & 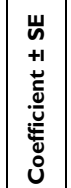 & 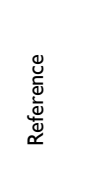 & & & 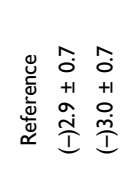 \\
\hline
\end{tabular}
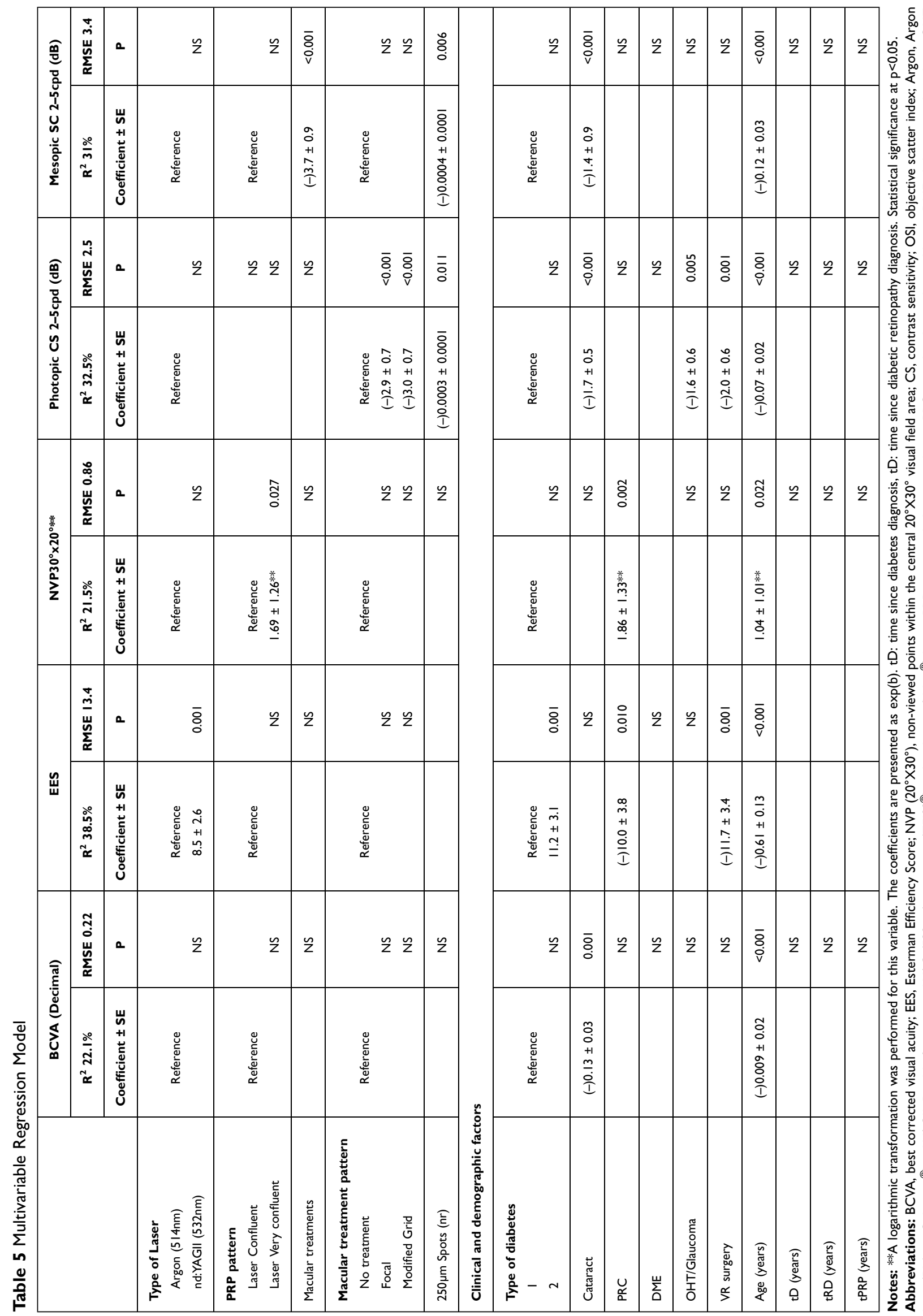

ż

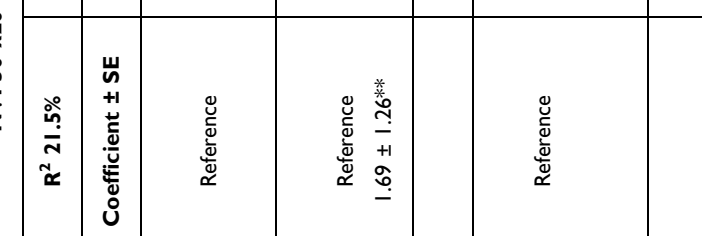

\begin{tabular}{|c|c|c|c|c|c|}
\hline 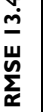 & a & $\bar{o}$ & $\tilde{z}$ & $\tilde{z}$ & $\tilde{z} \tilde{z}$ \\
\hline
\end{tabular}

岃

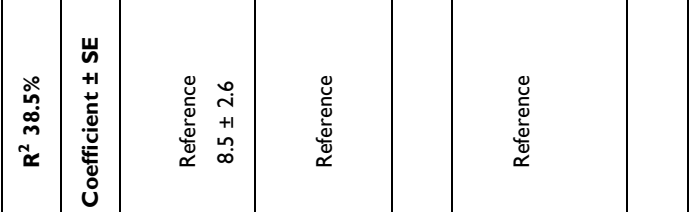

\begin{tabular}{|c|c|c|c|c|c|c|}
\hline $\mid \begin{array}{c}\tilde{N} \\
0 \\
w \\
\underline{w} \\
\sum_{\alpha} \\
\end{array}$ & a & $\tilde{z}$ & $\tilde{z}$ & $\tilde{z}$ & $\tilde{z} \tilde{z}$ & $\tilde{z}$ \\
\hline $\begin{array}{l}\frac{\circ}{\bar{i}} \\
\tilde{\mathbf{z}} \\
\tilde{\approx}\end{array}$ & 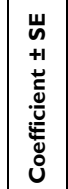 & 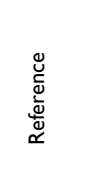 & 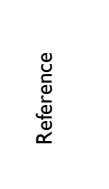 & & 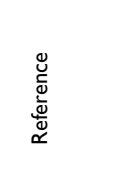 & \\
\hline
\end{tabular}

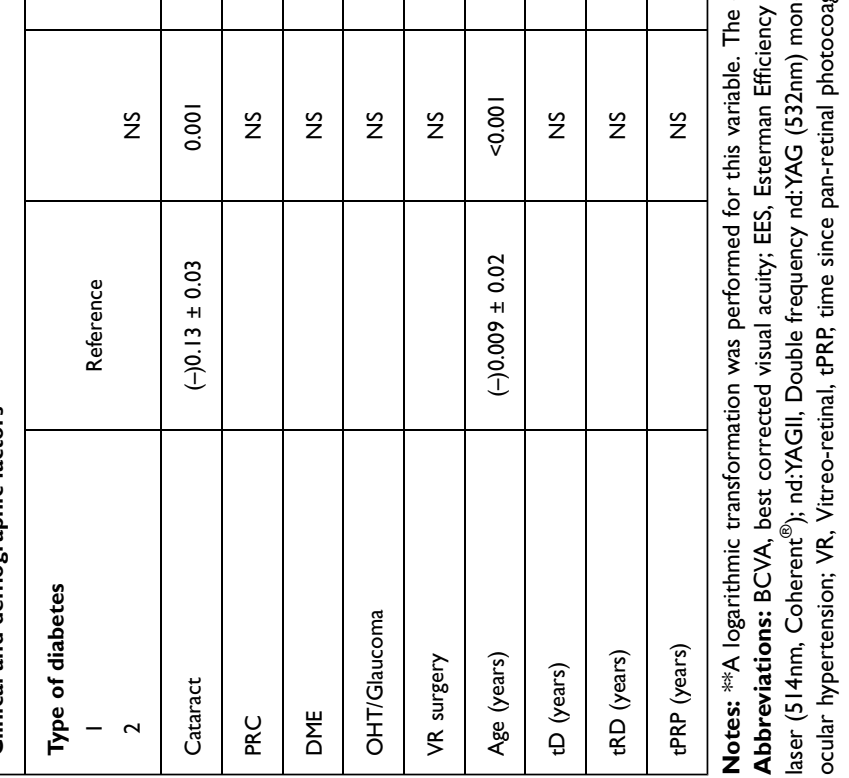


interfere significantly with the refractive performance of ocular media.

Concerning EBST, very acceptable results were found at average amplitudes and each quadrant presented only mild localised sensitivity losses. The EES was found at the highest quartile of normality and, after adjusting for age and history of VR surgery or PRC as confounding factors, Argon laser treatment was the only PRP factor associated with worse results. In the macular area, overall, the number of NVP $30^{\circ} \times 20^{\circ}$ was low. After the adjustment for age and history of PRC as confounders, the only treatmentrelated factor associated with worse outcomes was the very confluent PRP pattern. Despite the general idea of VF loss after PRP, there is no consensus in literature. In a study with a small population (10 eyes), there were no negative effects of treatment regarding VF in the short term (6 months). ${ }^{7}$ On the other hand, in a recent prospective 2-year study, Filek et a ${ }^{17}$ described a significant loss in VF evaluation in 16 patients undergoing PRP. In the scientific literature, no studies comprising long-term results in a large sample were found, as in the present study.

However, when translating these results into a quantifiable real-life parameter and according to the Decree-Law ${ }^{13}$ already stated, 15 (21\%) patients did not present minimum amplitudes of $\mathrm{VF}$ for driving nonprofessional light vehicles, on average after almost a decade of tPRP, in agreement with a series of 100 patients evaluated by Mackie et al. ${ }^{11}$ Several countries have contributed with studies in these populations and there seems to exist important legal differences to highlight: in the USA, not all states share the mandatory measurement of $\mathrm{CV}^{3}$, while in the United Kingdom patients undergoing PRP are required to inform the Driver and Vehicle Licensing Agency (DVLA). ${ }^{11}$ Many studies showed variable results in relation to the failure rate, regarding the minimum requirements by the DVLA (12-50\%), justifiable by the type of laser used, parameterization of the power, exposure time and spot size, and lens magnification. $^{7-10,18}$

Higher age was found to be a confounder for worse visual function results in all of evaluated parameters. With increasing life expectancy and the associated increase in prevalence of DR, more diabetics with PRP are expected to have systemic health conditions compatible with an active life and, therefore, this area of study will be of particular relevance and the negative effects of age should not be neglected.
The present study demonstrates the maintenance of PCS averages curve nearly in the lower limit of the reference interval but the MCS averages curve significantly under the reference interval, a decade after the treatment. In the same way as for VF, there is controversy in the literature about the deterioration of CS in patients undergoing PRP and there is lack of studies with long-term results and large sample sizes. In the 1990s, Mackie et al ${ }^{19}$ illustrated impairment in CS, in a cross-sectional study. On the other hand, Khosla et $\mathrm{a}^{20}$ prospectively demonstrated an initial but time-limited deterioration in the first three months. More recently, Preti et $\mathrm{al}^{21}$ corroborate these results, with stabilization at 6 months and demonstrate that adjuvant intravitreal treatment with Bevacizumab can be a protective factor, namely by decreasing DME. In the present study, the possible confounders were age and the presence of cataract for both PCS and MCS in the $2-5 \mathrm{cpd}$ interval and the history of OHT/Glaucoma or VR surgery only for the PCS. After the adjustment, and contrary to PRP patterns, the number of spots and the macular treatments were the only PRP-related factors associated with worse outcomes.

The significant number of type 1 diabetics in the present study deserved an individual analysis. After adjusting for the different clinical and treatment characteristics described above, type 1 diabetes predicted only worse EES and this reinforces the favorable risk-benefit ratio in carrying out these treatments at an early age in $\mathrm{DR}$, which is known to be more aggressive in type 1 diabetic patients.

The main strengths of the present study are the large sample size, the long time since PRP and the proportion of type 1 diabetic patients. The exclusion of patients which did not met the visual acuity criteria for driving according to the Portuguese law is the major limitation. However, the authors found it as the more reasonable way to expose a real-life analysis of visual function other than the central visual acuity measured in optimized conditions and at the same time highlighting the inclusion of these tests as pivotal for a thorough analysis in PRP patients. The retrospective nature, lack of baseline data or a control group could be understood as another two limitations of the study. However, regarding the second, some visual function tests described are not indicated for routine practice and would not be possible to perform some years ago in many patients included; regarding the third, as PRP is the gold standard since 1976, with no other approved therapeutic option, and 
non-treatment not being an option, it would always be impossible to make a comparison with a control group with such a large follow-up since PRP.

With the increase in life expectancy of patients with $\mathrm{DR}$, it is important to address the long-term treatment burden they will bring to healthcare services. Thus, when the PRP strategy as primary treatment for proliferative DR is compared prospectively with a strategy based on antiVEGF intravitreal injections, despite worse functional results in the PRP group reported at two years, ${ }^{22}$ a recent cost-effectiveness study ${ }^{23}$ point to an $85-90 \%$ decrease in cost-utility, extrapolated to the average 30-year life expectancy in these patients. In the present study, it is relevant to state that tD, tRD and, particularly, tPRP were not predictors of worse outcomes.

The present study includes eyes treated many years ago using conventional lasers with high temporizations and energies, within large retinal areas. By demonstrating good adjusted functional long-term results with these aggressive treatments our study values the role of PRP as a safe and cost-effective strategy to treat this increasing public health problem, in the present and future era of modern laser options and new tailored treatment strategies, less aggressive to retinal tissue. ${ }^{24}$

\section{Conclusion}

Pan-retinal photocoagulation can be considered an effective and safe treatment for long-term stabilization of diabetic retinopathy. Despite the retinal tissue aggression inherent to the procedure, the functional results achieved in our sample are compatible with an active life, allowing most of the patients included in the study to fit the requirements of Portuguese legislation for driving light vehicles, namely at the level of the binocular visual field. These results highlight the role of PRP in the management of diabetic retinopathy in an era with evolving less aggressive laser options.

\section{Acknowledgments}

The authors want to acknowledge all the support granted by the Head of the Ophthalmology Department of Centro Hospitalar e Universitário do Porto, Prof. Dr. Pedro Menéres.

\section{Disclosure}

The Authors declare that there is no conflict of interest.

\section{References}

1. The Diabetic Retinopathy Study Research Group. Preliminary report on effects of photocoagulation therapy. Am J Ophthalmol. 1976;81 (4):383-396. doi:10.1016/0002-9394(76)90292-0

2. Early Treatment Diabetic Retinopathy Study Research Group. Early photocoagulation for diabetic retinopathy. ETDRS report number 9 . Ophthalmology. 1991;98(5):766-785. doi:10.1016/S0161-6420(13) 38011-7

3. The Diabetic Retinopathy Study Research Group. Photocoagulation treatment of proliferative diabetic retinopathy. Clinical application of Diabetic Retinopathy Study (DRS) findings, DRS Report Number 8. Ophthalmology. 1981;88(7):583-600.

4. Diabetic Retinopathy Study Research Group.Photocoagulation treatment of proliferative diabetic retinopathy: relationship of adverse treatment effects to retinopathy severity. Diabetic retinopathy study report no. 5. Dev Ophthalmol. 1981;2:248-261.

5. Patz A, Fine S, Finkelstein D. Photocoagulation treatment of proliferative diabetic retinopathy: the second report of diabetic retinopathy study findings. Ophthalmology. 1978;85(1):82-106. doi:10.1016/ S0161-6420(78)35693-1

6. Subash M, Comyn O, Samy A, et al. The effect of multispot laser panretinal photocoagulation on retinal sensitivity and driving eligibility in patients with diabetic retinopathy. JAMA Ophthalmol. 2016;134(6):666-672. doi:10.1001/jamaophthalmol.2016.0629

7. Muqit MM, Wakely L, Stanga PE, Henson DB, Ghanchi FD. Effects of conventional argon panretinal laser photocoagulation on retinal nerve fibre layer and driving visual fields in diabetic retinopathy. Eye (London, England). 2010;24(7):1136-1142. doi:10.1038/ eye. 2009.308

8. Pearson AR, Tanner V, Keightley SJ, Casswell AG. What effect does laser photocoagulation have on driving visual fields in diabetics? Eye (London, England). 1998;12(1):64-68. doi:10.1038/eye.1998.12

9. Buckley SA, Jenkins L, Benjamin L. Fields, DVLC and panretinal photocoagulation. Eye (London, England). 1992;6(6):623-625. doi:10.1038/eye.1992.134

10. Hulbert MF, Vernon SA. Passing the DVLC field regulations following bilateral pan-retinal photocoagulation in diabetics. Eye (London, England). 1992;6(5):456-460. doi:10.1038/eye.1992.96

11. Mackie SW, Webb LA, Hutchison BM, Hammer HM, Barrie T, Walsh G. How much blame can be placed on laser photocoagulation for failure to attain driving standards? Eye (London, England). 1995;9(4):517-525. doi:10.1038/eye.1995.118

12. Williamson TH, George N, Flanagan DW, Norris V, Blamires T. Driving standards: visual fields in diabetic patients after pan-retinal photocoagulation: vision in vehicles III. 1991;265-272.

13. Diário da República.Decreto-lei número 40/2016. Série I ed. Diário da República. [Decree-law number 40/2016. Series 1 ed. Republic Diary]. Portuguese Government; 2016:64.

14. Schmidt-Erfurth U, Garcia-Arumi J, Bandello F, et al. Guidelines for the management of diabetic macular edema by the European Society of Retina Specialists (EURETINA). Ophthalmologica. 2017;237 (4):185-222. doi:10.1159/000458539

15. Lee R, Wong TY, Sabanayagam C. Epidemiology of diabetic retinopathy, diabetic macular edema and related vision loss. Eye Vis (Lond). 2015;2:17.

16. Nielsen NV. The prevalence of glaucoma and ocular hypertension in type 1 and 2 diabetes mellitus. An epidemiological study of diabetes mellitus on the island of Falster, Denmark. Acta Ophthalmol (Copenh). 1983;61(4):662-672. doi:10.1111/j.1755-3768.1983. tb04357.x

17. Filek R, Hooper P, Sheidow T, et al. Structural and functional changes to the retina and optic nerve following panretinal photocoagulation over a 2-year time period. Eye (London, England). 2017;31 (8):1237-1244. doi:10.1038/eye.2017.66 
18. Williamson TH Driving standards visual fields in diabetic patients after panretinal laser photocoagulation. 1991.

19. Mackie SW, Walsh G. Contrast and glare sensitivity in diabetic patients with and without pan-retinal photocoagulation. Ophthalmic Physiol Opt. 1998;18(2):173-181. doi:10.1046/j.14751313.1998.00339.x

20. Khosla PK, Rao V, Tewari HK, Kumar A. Contrast sensitivity in diabetic retinopathy after panretinal photocoagulation. Ophthalmic Surg. 1994;25(8):516-520.

21. Preti RC, Ramirez LM, Monteiro ML, Carra MK, Pelayes DE, Takahashi WY. Contrast sensitivity evaluation in high risk proliferative diabetic retinopathy treated with panretinal photocoagulation associated or not with intravitreal bevacizumab injections: a randomised clinical trial. Br J Ophthalmol. 2013;97(7):885-889. doi:10.1136/bjophthalmol-2012-302675
22. Gross JG, Glassman AR, Jampol LM, et al. Panretinal photocoagulation vs intravitreous ranibizumab for proliferative diabetic retinopathy: a randomized clinical trial. JAMA. 2015;314(20):2137-2146. doi:10.1001/jama.2015.15217

23. Lin J, Chang JS, Smiddy WE. Cost evaluation of panretinal photocoagulation versus intravitreal ranibizumab for proliferative diabetic retinopathy. Ophthalmology. 2016;123(9):1912-1918. doi:10.1016/j. ophtha.2016.05.037

24. Yun SH, Adelman RA. Recent developments in laser treatment of diabetic retinopathy. Middle East Afr J Ophthalmol. 2015;22 (2):157-163. doi:10.4103/0974-9233.150633

Diabetes, Metabolic Syndrome and Obesity: Targets and Therapy

\section{Publish your work in this journal}

Diabetes, Metabolic Syndrome and Obesity: Targets and Therapy is an international, peer-reviewed open-access journal committed to the rapid publication of the latest laboratory and clinical findings in the fields of diabetes, metabolic syndrome and obesity research. Original research, review, case reports, hypothesis formation, expert opinion and commentaries are all considered for publication. The manuscript management system is completely online and includes a very quick and fair peer-review system, which is all easy to use. Visit http://www.dovepress.com/testimonials.php to read real quotes from published authors. 